Recepción: 14/11/2018

Aceptación: 08/01/2019

Publicación: 05/02/2019

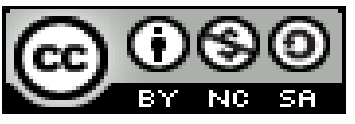

Ciencias sociales y políticas

Artículo de revisión

\title{
La inserción al mundo laboral de las personas con capacidades especiales
}

The insertion in the labor world of people with special abilities

\section{A inserção no mundo do trabalho de pessoas com habilidades especiais}

\author{
María Paulina Poma-Copa ${ }^{\text {I }}$ \\ paulina.poma@espoch.edu.ec \\ Héctor Andrés Torres-Alta II \\ hector.toorre@espoch.edu.ec \\ Gustavo Efraín Carrera-Oña ${ }^{\text {III }}$ \\ gcarrera@espoch.edu.ec
}

Correspondencia: paulina.poma@espoch.edu.ec

I Magíster en Calidad, Seguridad y Ambiente, Ingeniera Química, Docente Escuela Superior Politécnica del Chimborazo, Riobamba, Ecuador.

II Magíster en Gestión Industrial y Sistemas Productivos, Ingeniero Industrial, Docente Escuela Superior Politécnica del Chimborazo, Riobamba, Ecuador.

III Magíster en Seguridad Industrial Mención Prevención de Riesgos y Salud Ocupacional, Ingeniero Industrial, Tecnólogo Mecánico, Docente Escuela Superior Politécnica del Chimborazo, Riobamba, Ecuador. 


\section{Resumen}

El presente se ha elaborado como un artículo de revisión, en el cual se aborda el conocimiento disponible en cuanto a las personas con capacidades especiales, su origen sus tipos la discriminación hacia estas personas con su derecho al trabajo y posibles estrategias para su inserción laboral, construyendo un análisis con argumentos fundamentados en la literatura científica existente. El estudio se abordó bajo la metodología de análisis de contenido y contempló la revisión de documentos legales y normativos, y unidades de análisis. Como resultado se evidenció que la concepción de discapacidad tuvo una tendencia hacia el modelo médico o rehabilitador, seguida del modelo biopsicosocial, además de una relación y evolución acorde entre las concepciones de discapacidad y la terminología para nombrar a la población objetivo, por lo cual se insiste en la necesidad de que se les identifique como personas con capacidades especiales. En relación con la inclusión laboral se encontraron estrategias propias del empleo protegido y del empleo abierto u ordinario, además de otras estrategias que emergieron del análisis. Se concluye que existe la necesidad de aunar esfuerzos que conlleven a la reglamentación e implementación de políticas y programas vigentes con el fin de lograr un tratamiento igualitario y equitativo para las Personas con capacidades especiales.

Palabras claves: discapacidad; inclusión laboral; empleo protegido; personas con capacidades especiales.

\section{Summary}

The present has been prepared as a review article, which addresses the available knowledge regarding people with special abilities, their origin, their types, the discrimination towards these people with their right to work and possible strategies for their labor insertion, building an analysis with arguments based on the existing scientific literature. The study was addressed under the methodology of content analysis and contemplated the review of legal and regulatory documents and units of analysis. As a result, it was evident that the concept of disability had a tendency toward the medical or rehabilitative model, followed by the biopsychosocial model, as well as a relationship and evolution consistent between the concepts of disability and the terminology to name the target population, which is why insists on the need to be identified as people with special abilities. In relation to labor inclusion, strategies were found for protected employment and open or ordinary employment, in addition to other strategies that emerged from 
the analysis. It is concluded that there is a need to combine efforts that lead to the regulation and implementation of current policies and programs in order to achieve equal and equitable treatment for people with special abilities.

Keywords: disability; labor inclusion; protected employment; people with special abilitie

\section{Resumo}

O presente foi elaborado como um artigo de revisão, que aborda o conhecimento disponível sobre pessoas com habilidades especiais, sua origem, seus tipos, a discriminação em relação a essas pessoas com seu direito ao trabalho e possíveis estratégias para sua inserção laboral, construir uma análise com argumentos baseados na literatura científica existente. O estudo foi abordado sob a metodologia de análise de conteúdo e contemplou a revisão de documentos legais e regulamentares e unidades de análise. Como resultado, tornou-se claro que o conceito de deficiência teve uma tendência para o modelo médico ou reabilitação, seguido pelo modelo biopsicossocial, além de um relacionamento e desenvolver-se em linha entre os conceitos de deficiência e terminologia para citar a população-alvo, que é insiste na necessidade de ser identificado como pessoas com habilidades especiais. Em relação à inclusão laboral, foram encontradas estratégias para emprego protegido e emprego aberto ou ordinário, além de outras estratégias que emergiram da análise. Conclui-se que há a necessidade de combinar esforços que levem à regulamentação e implementação de políticas e programas atuais, a fim de alcançar tratamento igual e equitativo para pessoas com habilidades especiais.

Palavras-chave: incapacidade; inclusão laboral; emprego protegido; pessoas com habilidades especiais

\section{Introducción}

En un principio se pretendió presentar en este artículo el trabajo de investigación La gestión de seguridad industrial y su incidencia sobre el personal con capacidades especiales de la cooperativa de producción industrial del calzado en el cantón penipe provincia de Chimborazo, pero se entendió que antes de realizar esto, era necesario primero tener clara la posición de teorías y teóricos que sustentaran dicha investigación. Por ello se procedió a elaborar este trabajo, según lo planteado por Cuevas (2013), asumiéndolo como un artículo de revisión y abordarlo revisando el conocimiento disponible al respecto y construyendo un análisis con argumentos fundamentados del tema en estudio, en la literatura científica existente. 
Para efectos del presente trabajo, de manera operacional se define personas con capacidades especiales como, aquellas personas que tienen algún impedimento físico, mental o sensorial. Estos impedimentos probablemente interfieran o dificulten en gran manera la actividad cotidiana de las personas por lo que, al padecer de las mismas, logran adquirir y desarrollar habilidades especiales, es decir que sus actividades cotidianas o laborales se desenvuelven de manera distinta a todas las actividades de una persona sin impedimento alguno, pero esto no quiere decir que no las puedan llevar a cabo de manera correcta. (Organización de las Naciones Unidas - ONU. 2006). Es necesario señalar, que en la mayoría de la literatura revisada se habla de personas con discapacidad, por respeto a los autores consultados se mantiene el termino discapacidad en este artículo, a pesar de que los autores de este artículo preferirían que se usara capacidades especiales Las personas con capacidades especiales al igual que otros grupos poblacionales, han visto vulnerado el ejercicio de muchos de sus derechos fundamentales, como consecuencia de su condición estructural que las ubica en situación de desventaja, entendida esta última como una desigualdad en relación con el disfrute de los derechos frente al resto de la sociedad. Ante las constantes barreras a las que se ven enfrentadas las personas con discapacidad para ser considerados como ciudadanos de manera plena y efectiva en la, organismos de carácter internacional han creado documentos que tienen como propósito reivindicar los derechos de los que son objeto.

Es así como la asamblea general de la ONU en el 2006, aprobó el documento conocido como la Convención sobre los Derechos de las Personas con Discapacidad, con el objeto de promover, proteger y asegurar el goce de los derechos humanos por todas estas personas, el cual como instrumento internacional busca ratificar la plena igualdad ante la ley de estas personas. Dentro de su preámbulo se destacan, entre otras, las condiciones de pobreza en las que viven la mayoría de las personas con discapacidad y la necesidad fundamental de mitigar los efectos negativos que dichas condiciones les imponen. En el artículo 27 se menciona el derecho al trabajo y al empleo que poseen las personas con discapacidad para ser ejercido en condiciones justas y favorables iguales a las demás personas, en un mercado y un entorno que sean abiertos, accesibles e inclusivos, en el sector público o en el privado, donde para promoverlo se implementen acciones afirmativas, incentivos y otras medidas. 
El Informe Mundial sobre la Discapacidad de la OMS (2011), que basa su concepción de discapacidad como parte de la condición humana, destaca que casi todas las personas en algún momento de su vida tendrán una discapacidad temporal o permanente y hace enumeraciones puntuales en el tema de pobreza y discapacidad al igual que la Convención. Las estimaciones de este informe reportan que un $15 \%$ de la población mundial vive con alguna discapacidad.

A pesar de las diferentes medidas implementadas en el ámbito legal y normativo, la grave situación de exclusión a la que se ven expuestas las personas con capacidades especiales en el mercado laboral, hace que sea inminente la toma de acciones encaminadas hacia la superación de las barreras que imposibilitan el logro de la inclusión laboral de este colectivo, de manera que se propicien condiciones idóneas para el logro de un proyecto de vida digno en la etapa de vida adulta, que brinde autonomía para sí mismas y para las personas que de éstas dependen, con el fin de mitigar los efectos adversos que trae consigo la pobreza, no solo en relación con la obtención de ingresos económicos equitativos sino con el ejercicio del rol como trabajadores dentro de la sociedad, que se traduce en inclusión en la vida social.

Para comprender con más especificidad la magnitud de la problemática de exclusión laboral a la que se ve expuesta esta población, Rodríguez y Rico (2009) establecen que en la brecha laboral en contra de las personas con capacidades especiales se traduce en desventajas relacionadas con el goce de otros derechos como la salud y la seguridad social, que dependen en parte de la participación laboral. En concordancia, Peñas (2004) encuentra que el desempleo puede ser interpretado como una privación de ciudadanía y una vulneración de los derechos al trabajo y la seguridad social. Se suma a lo anterior, lo expresado por Parra (2004), al citar que no se trata solamente del reconocimiento formal de los derechos, sino de poder ejercerlos de manera efectiva en condiciones de igualdad.

\section{Personas con capacidades especiales}

Las personas con capacidades especiales son todas aquellas personas que por causas congénitas o adquiridas presenten alguna disfunción o ausencia de sus capacidades de orden físico, mental, intelectual, sensorial o combinaciones de ellas; de carácter temporal, permanente o intermitente, que al interactuar con diversas barreras le impliquen desventajas que dificultan o impidan su 
participación, inclusión e integración a la vida familiar y social, así como el ejercicio pleno de sus derechos humanos en igualdad de condiciones con los demás.

Según Cuervo y Trujillo. (2004), las personas con discapacidad, por la diferencia que presentan, que tiene efectos sociales, al enfrentarse a un entorno hostil, no pensado para ellas, parten de una situación de objetiva desventaja que repercute en sus posibilidades de participación plena en el curso ordinario de la vida social, en las mismas o parecidas condiciones que el resto de los ciudadanos. A efectos prácticos, las personas con discapacidad son, en muchos casos, ciudadanos de segunda. Pese a las proclamaciones formales de igualdad que tienen su reflejo tanto en instrumentos jurídicos internacionales, como en normas de ámbito nacional, la equiparación efectiva entre personas con y sin discapacidad no pasa de ser un buen propósito. Precisamente, la discapacidad como parte de la diversidad humana, encarna una diferencia, no siempre valorada adecuadamente. Poder hacerlo, supone identificar y comprender cabalmente su especificidad y diferenciarla objetivamente de las otras diferencias para dar la respuesta ajustada a necesidades y demandas de sus portadores.

En conjunto a lo expresado las personas con capacidades especiales son seres humanos como cualquier otro, sólo que presentan una condición de vida diferente; la cual puede ser superada con la ayuda de personas cercanas a ellos para que se incorporen en la sociedad por medio de avances en las áreas de: la medicina, educación familiar y laboral.

\section{Origen de la discapacidad}

Se debe tener presente que, la discapacidad está mucho más generalizada de lo que comúnmente se reconoce. Padilla (2010) plantea que las formas más difundidas son las limitaciones físicas, la enfermedad crónica, el retraso mental y las incapacidades de los sentidos. Hoy en día existen muchas malformaciones congénitas se deben a condiciones dañinas en la vida de las personas. Por eso, se podría prevenir muchas discapacidades si todas las niñas y mujeres comieran suficientes alimentos nutritivos, se pudieran proteger contra las sustancias químicas tóxicas en el trabajo y en el ambiente, y recibieran buena atención de salud, incluyendo atención para el embarazo y el parto. 
Existe una genética de discapacidad en el cual una de ella y la más influyente son la pobreza y la desnutrición. Hay más discapacidad entre la gente pobre porque viven y trabajan en ambientes peligrosos y hacinados donde falta saneamiento, suficientes alimentos nutritivos, agua potable y acceso a la educación. Bajo esas condiciones, enfermedades como la tuberculosis y la polio se transmiten más fácilmente, y las discapacidades graves que causan son más frecuentes.

Según Palacios (2008). la discapacidad puede ocurrir tanto por accidentes laborales como genéticamente o de enfermedades que son heredadas o que son transmitida por la madre y su cuidado, el autor indica que estas personas presentan una disminución de sus capacidades físicas o intelectuales, a su vez poseen miembros amputados, discapacidades psíquicas, daños en la medula espinal, daño visual y auditivo permanente. El autor antes mencionado, manifestó que el origen congénito se produce por un trastorno durante el desarrollo embrionario o durante el parto puede ser a consecuencia hereditarias o ambientales, esto se distingue dos tipos de origen congénitas como hereditarias (genéticas) y no hereditarias.

Este autor señala además que, el problema continúa creciendo, impulsado varios factores que incrementan el número de personas con discapacidad. La población mundial está creciendo, y la producción mundial de alimentos apenas puede ajustarse a su ritmo; las personas viven más tiempo con mejores condiciones sociales y atención médica; la industrialización y la urbanización se están propagando rápidamente en el mundo en desarrollo.

Dentro del origen la discapacidad, menciona la adquirida de manera común, que son causadas por accidente o por enfermedades, esta discapacidad va asociada a distintas causales como accidentes, traumas, intoxicaciones por medio ambientales o medicamentos, además has discapacidades causadas en enfermedades discapacitantes como el tener un tumor, infecciones, procesos degenerativos, problemas hormonales y metabólicos, entre otros. Esta discapacidad común también es provocada como es en el caso de la mujer embarazada ya que ellas son principal fuente de que seas tanto una enfermedad que un accidente, las personas con baja movilidad por operaciones leves los cuales producen una disminución de sus capacidades en un tiempo determinado ya establecidos.

Algunas malformaciones congénitas son causadas por enfermedades que tuvo la madre mientras estaba embarazada. Por eso, las mujeres embarazadas deben hacerse pruebas para detectar esas 
infecciones y deben recibir tratamiento si alguna prueba da un resultado positivo. Se puede decir que las personas que poseen una discapacidad por accidente o enfermedad son personas que al igual que cualquier otra, pueden sobrevivir en el mundo de hoy en día, ellos también pueden ser emprendedores y capaces de lograr cualquier tipo de trabajo dependiendo claro de su capacidad, son personas que no desean ser excluidos del mundo del trabajo ya sea por tener alguna patología genética o por algún accidentes ocurrido, hoy en día se está combatiendo de que ellos tienen derecho a ser incluidos en la sociedad y no tratarlos como personas que no iguales a uno si no incluirlos como personas trabajadores que ayudan aportar a la empresa. (Palacios 2008).

Otros de los orígenes de la discapacidad es la adquirida a nivel laboral, que son causadas por accidente o por enfermedades ocupacionales. Las cuales son condiciones de trabajo peligrosas si uno trabaja muchas horas sin descansar, es más probable que tenga algún accidente. Las personas que trabajan en fábricas, minas o campos agrícolas pueden exponerse a máquinas, herramientas o sustancias químicas peligrosas. Los accidentes como el trabajo excesivo y el contacto con sustancias químicas pueden causar discapacidades. Además, cada vez más personas están sufriendo lesiones permanentes debido a la violencia en el trabajo, a veces, los supervisores usan amenazas y violencia para presionar al trabajador más. Muchas personas sufren lesiones en casa, que les puede ocasionar una discapacidad. Las discapacidades muchas veces también se deben a accidentes en el trabajo, sobre todo en los sectores menos reglamentados, como la construcción, la agricultura, la minería y las microempresas. Los trabajadores muchas veces usan sustancias químicas en la fábrica o en el campo sin que se les haya enseñado cómo usarlas sin peligro, o sin siquiera que sepan si son peligrosas.

Existen enfermedades ocupacionales toda condición patológica inducida por el trabajo continuando los estados patológicos contraídos o agravados con ocasión del trabajo o exposición al medio en el que el trabajador o la trabajadora se encuentra obligado a trabajar, tales como los imputables a la acción de agentes físicos y mecánicos, condiciones disergonómicas, meteorológicas, agentes químicos, biológicos, factores psicosociales y emocionales, que se manifiesten por una lesión orgánica, trastornos enzimáticos o bioquímicos, trastornos funcionales o desequilibrio mental, temporales o permanentes (Laloma 2007). 
Se puede inferir que las personas con discapacidad son personas que tienen potencial necesario para incorporarse a la fuerza de trabajo como un empleado, trabajadores independientes o empresarios y que ellos deseen hacerlo. Con frecuencia se cree que las personas con discapacidad no están preparadas para el trabajo y nos le dan la oportunidad de demostrar lo contrario que son capaces de ser unas personas trabajadoras, otras razones por las cuales no les dan esa oportunidad es porque no tienen una adecuada educación o una formación profesional en el cual no le facilitan su incorporación al empleo.

\section{Tipos de discapacidad}

Para identificar las características de los grandes grupos se ha recurrido a Clasificación Internacional del Funcionamiento de la Discapacidad y de la Salud (CIF, 2001), para brindar una clasificación con un lenguaje unificado y estandarizado agrupando las deficiencias en las categorías física, mental y sensorial, teniendo siempre presente la gran heterogeneidad que existe dentro de cada uno.

La deficiencia física, es un esquema que responde a objetivos de delimitación dentro de un espectro amplio. No obstante, su uso puede ayudar a comprender la compleja realidad de las discapacidades. Se considerará que una persona tiene deficiencia física cuando padece anomalías orgánicas en el aparato locomotor o las extremidades (cabeza, columna vertebral, extremidades superiores y extremidades inferiores). También se incluyen las deficiencias del sistema nervioso, referidas a las parálisis de extremidades superiores e inferiores, paraplejías y tetraplejías y a los trastornos de coordinación de los movimientos, entre otras. Un último subconjunto recogido en la categoría de discapacidades físicas es el referido a las alteraciones viscerales, esto es, a los aparatos respiratorio, cardiovascular, digestivo, genitourinario, sistema endocrino-metabólico y sistema inmunitario.

En todos los casos de deficiencias de carácter físico el eje problemático en torno al cual se estructura la trama de la integración, es la autonomía personal, ya que, aunque en cada etapa del ciclo vital las expectativas en torno a la autonomía son distintas, como también lo son entre las personas que no padecen discapacidad, se trata de un elemento esencial desde el punto de vista de la calidad de vida. 
Pues bien, hablar de autonomía supone referirse a ámbitos tan variados como el laboral, el educativo, la comunicación social y por supuesto la accesibilidad, que aglutina a todas estas facetas vitales. La escasa participación en actividad y empleo, el déficit y el desajuste educativo, así como la sobreprotección familiar, que redundan en la falta de autonomía, son problemas comunes a todas las personas con discapacidad. Pero tal vez se manifiesten de forma especialmente reconocible en términos de accesibilidad en aquellas personas que tienen muy reducida su capacidad de movimiento, como los usuarios de sillas de ruedas.

Al hablar de deficiencias sensoriales es necesario recordar que las categorías de análisis presentan limitaciones en la descripción de la realidad para la que se aplican. No obstante, asumiendo los criterios de clasificación empleados en la encuesta, son útiles como aproximación al tamaño y sobre todo a la composición del colectivo resultante. La categoría deficiencias sensoriales, incluye a quienes presentan trastornos relacionados con la vista, el oído y el lenguaje. (Angarita 2014).

\section{La discriminación de personas con discapacidad}

Jiménez, y Agustín (2005) plantean que, la discriminación se funda en prejuicio que se han heredado a lo largo de la historia, sobre las capacidades y conductas que supuestamente tienen las personas con discapacidad. Estos prejuicios finalmente determinan las expectativas que se generan sobre ellas. Existen tres tipos de discriminación hacia estas personas que se presentan con mayor frecuencia en nuestra sociedad. Estos autores refieren tipos de discriminación hacia las personas con discapacidad:

Discriminación positiva: acciones sobreprotección/paternalismo que finalmente deriva en una discriminación inconsciente. Una familia que tiene un hijo con problema de discapacidad, y no lo dejan salir a jugar con los vecinos a la calle por temor a que le pase algo, es una familia que estimula la dependencia de su hijo, perjudicándolo en su integración social.

Discriminación sistemática: también llamado de impacto adverso o indirecto. Es la más compleja de todas y consiste en calificarlas como a cualquier otra persona. Un ejemplo de ello es tener una política empresarial que exige que todos los candidatos a un puesto determinado, deban pasar un examen oral, lo cual perjudica a aquellos que tienen una profunda sordera. Lo que se espera de 
las empresas es que traten a las personas con discapacidad equitativamente no igualitariamente para que a nadie le sea negada la oportunidad de trabajar en relación a su habilidad.

A través de los años la discriminación hacia las personas con discapacidad ha creado grandes barreras para que las mismas puedan ser insertadas al campo laboral tal como lo establece la Organización Internacional del Trabajo (2014) en su primer informe global sobre discriminación en el trabajo:

\section{Trabajo y discapacidad}

Los valores y nociones relacionados con el concepto de trabajo han desempeñado un importante papel en el establecimiento de los roles asumidos por las personas con discapacidad en la sociedad, e influyen a su vez, en las concepciones que han surgido sobre la discapacidad y su relación con la capacidad para realizar un trabajo que permita el acceso a una vida digna, en el ejercicio de los derechos como ciudadanos.

Tal como lo plantea Barnes (1998) la tradición de cuidar a los enfermos y menos favorecidos por medio de las limosnas, es así como desde inicios del siglo XV la tradición de la caridad cristiana permitió la supervivencia de las personas que no poseían recursos, entre las cuales se encontraban las personas con capacidades especiales, quienes fueron ingresadas en hospitales medievales que poseían más un carácter médico que eclesiástico. A comienzos del siglo XVI la riqueza y el poder de la iglesia imperante por varios años, experimentaron un notable descenso que llevó a un gran número de personas a depender de la caridad pública en general.

Tal como lo afirma Palacios (2008), como medida de respuesta ante la situación experimentada por las personas denominadas como marginados, de los que hacían parte entre otros, los pobres, los enfermos y las personas con discapacidad nombradas con el apelativo de inválidos, se creó en Inglaterra la Ley de los Pobres en 1601. Esta ley se compuso con la categorización de los pobres y la actuación del Estado a través de las parroquias, jueces de paz condónales e inspectores de pobres, dicha ley representó el primer reconocimiento oficial de la necesidad de la intervención del Estado en la vida de las personas con insuficiencias. Tal providencia puede ser considerada como un importante logro para su momento histórico, pero al revisar medidas que aún siguen siendo aplicadas en muchos países, especialmente europeos, la Ley de los Pobres se constituye 
como el antecedente más importante en relación con el asistencialismo del que todavía hoy son objeto las personas con discapacidad.

El desarrollo de la sociedad industrial occidental al afianzarse en el siglo XIX con el impulso de la sociedad capitalista de occidente, trae como resultado la exclusión de las personas con insuficiencias del mundo laboral, al no poder ajustarse al nuevo ritmo de trabajo impuesto en las fábricas. A partir de estas relaciones a las personas con discapacidad se les denominó como improductivas para la sociedad, e incapacitadas debido a las insuficiencias que evidenciaban para realizar trabajos de acuerdo con la producción a gran escala, donde solo se daba cabida a aquellos que presentaban características compatibles con los estándares de normalidad propios de la época y de los sistemas de producción.

A su vez, Angarita, (2014) señala que en la mayor parte del siglo XX el trabajo se estructuró alrededor de los principios gemelos de la competencia entre los trabajadores individuales y el logro del mayor beneficio, los cuales influyeron de manera directa en la exclusión de las personas con discapacidad del mercado laboral. Los únicos acontecimientos de dicho siglo durante los cuales las personas con discapacidad fueron objeto de una importante incorporación a la industria son la Primera y la Segunda Guerra Mundial, debido a que el objetivo del trabajo que se realizaba no era obtener el máximo beneficio sino luchar contra el enemigo común.

Las personas con discapacidad al verse excluidas en diversas ocasiones del ejercicio del derecho al trabajo a través de la modalidad de un contrato subordinado y de las garantías que este brinda, se han visto en la necesidad de ejercer el trabajo de manera independiente por medio de la informalidad, enfrentándose a condiciones de vida poco dignas que se reflejan, entre otras, por la obtención de salarios menores al mínimo legal vigente, que imposibilitan el acceso a los beneficios que otorga la seguridad social en relación con derechos fundamentales como la salud.

Es posible concluir que hoy en día el trabajo es considerado como una de las principales categorías de análisis social, político y económico, por la influencia directa que ejercen sobre éste las constantes transformaciones de la sociedad contemporánea. 


\section{Derecho al trabajo de las personas con capacidades especiales}

Sin embargo, como lo hemos planteado anteriormente, las leyes internacionales les brindan a las personas con discapacidad el derecho a un trabajo decente, el cual según Stang (2011). entre otras palabras indica que con frecuencia es negado por las organizaciones tanto públicas como privadas por diferentes motivos internos, sin pensar o importarles que las personas con discapacidad, en particular las mujeres con discapacidad, se enfrentan a enormes barreras de oportunidades en el mundo del trabajo, siendo estas las más necesitadas económicamente por sus gastos médicos, que representan un factor fundamental para llevar una vida digna como lo determinan las leyes nacionales e internacionales, esto en comparación con las personas sin discapacidad. Los esfuerzos de la OIT para incluir personas con discapacidad cubren toda su gama de actividades, incluyendo sus prácticas internas y sus alianzas con otras agencias como es el caso de la Organización de las Naciones Unidas (ONU) quienes son garantes de cumplir con los convenios que ellos establecen.

A tal efecto Vidal y Cornejo (2012), comentan que, integrar a una persona con discapacidad a un ambiente de trabajo, es integrarlo a la comunidad, es lograr formar un equipo de trabajo consolidado, en donde cada uno de los miembros que los integran, tienen determinadas cualidades, valores, habilidades y conocimientos que los hacen únicos, en otras palabras que, integrar a una persona con discapacidad requiere de una planificación estratégica, para lograr el objetivo principal que es el integrarlo en sociedad, ya que de lo contrario sería una contratación por caridad sin lograr ningún beneficio social para esa persona. En tal sentido, la gerencia encargada de la administración del Recurso Humano, debe estar preparada para el reclutamiento, selección, inclusión y socialización del personal que realizará sus funciones de una mejor manera, y para esto es necesario seguir una cantidad de procesos que se han ido mejorando constantemente.

Por otra parte, Stang (2011). argumenta que para las empresas en el área de Recursos Humanos deben aportar información para que se pueda desarrollar una política de inclusión laboral y social de trabajadores con discapacidad, considerar la necesidad de adaptaciones del entorno físico o funcional del puesto y reevaluar los riesgos laborales del puesto de acuerdo con las características de cada trabajador. 
Cabe destacar, que la discapacidad no tiene por qué suponer anticipadamente una brecha importante en las habilidades del trabajador, la perspectiva tiene que ser la de valorar en conjunto con el candidato, cuáles son las principales dificultades derivadas de su discapacidad y que tienen una repercusión importante en las tareas encomendadas. La valoración conjunta empresa-persona permitirá un mejor ajuste con el puesto de trabajo, hará que el trabajador se sienta valorado y escuchado, afianzará la relación trabajador-empresario, en general obtendrán un mayor grado de satisfacción personal y responsabilidad.

\section{Estrategias para la inclusión laboral de Personas con capacidades especiales}

Según lo planteado por Laloma, (2007). Se puede asumir que el empleo protegido consiste en aquel que se ha generado para las personas con discapacidad en empresas ordinarias, que cumplen determinadas características para promover su incorporación en el mercado laboral Esta modalidad de empleo se ha dado en gran cantidad de países ajustándose a las características y necesidades específicas del contexto y de población. Puede darse en contextos tanto públicos como privados, y una de sus principales características es la de facilitar la transición de las personas con discapacidad al empleo ordinario.

Por otro lado, el empleo abierto consiste en una modalidad de empleo que también se le conoce como empleo ordinario, normalizado o regular. Esta modalidad es en la que se desenvuelven generalmente la gran mayoría de trabajadores en empresas privadas o públicas. Este tipo de empleo es el que se da en contextos donde la mayoría de trabajadores no tienen ningún tipo de discapacidad.

Para Laloma (2007), las personas con discapacidad que se acogen a esta modalidad pueden haber sido contratadas por alguna subvención o programa de integración laboral de las personas con discapacidad en el empleo ordinario, por un proceso de selección que no se relaciona con ningún programa específico que beneficie a la empresa, porque se adquirió la discapacidad laborando en la empresa pública o privada, o en cumplimiento de la cuota de reserva.

\section{A manera de conclusión}

Uno de los aspectos de mayor relevancia social en los últimos años, ha sido la inserción de las personas con discapacidad en el campo laboral. En torno a él giran diversos enfoques y 
argumentos que resaltan su importancia, tanto en el ámbito económico, como en el social, político y cultural.

El trabajo no sólo dignifica a la persona con capacidades especiales, también le permite su propia realización, con la cual eleva su autoestima, además de ofrecerle la oportunidad de obtener los recursos económicos para satisfacer sus necesidades y las de sus familiares. En este contexto, se puede afirmar que el trabajo les da sentido a sus vidas, y se sienten contribuyendo a la sociedad, versus el estigma tradicional de que son una carga para sus familias y el Estado.

La inserción de personas con capacidades especiales, comprende la inclusión en los aspectos cotidianos, sociales, laborales, entre otros contextos del quehacer humano. La inserción de estas personas en la sociedad puede presentar itinerarios muy diversos que se mueven entre la inclusión y la exclusión. En el polo de la inclusión se incrementan la calidad de vida y el sentimiento de realización personal y profesional, en el polo de la exclusión se acentúan la precariedad económica y los sentimientos de fracaso y marginación social.

En los últimos años se ha evidenciado una evolución del concepto de integración hacia el de inclusión el cual transita de pensar en el individuo, que se integra, a considerar el contexto que debe satisfacer las necesidades de todos. No se trata de normalizar al individuo, sino al entorno en el cual se desenvuelve.

La inserción laboral como mecanismo de inclusión, es uno de los aspectos que mayor relevancia ha tenido a través del tiempo en la vida del hombre es el trabajo. En torno a él giran diversos enfoques y argumentos que resaltan su importancia, tanto en el ámbito económico, como en el social, político y cultural.

El trabajo no sólo dignifica a la persona, también le permite su propia realización, con la cual eleva su autoestima, además de ofrecerle la oportunidad de obtener los recursos económicos para satisfacer sus necesidades y las de sus familiares. En este contexto, se puede afirmar que el trabajo representa para el individuo un campo rico de acción, una forma de integrarse responsable y creadoramente a la vida social y es una puerta abierta a las múltiples oportunidades de desarrollo.

Integrar a las personas con capacidades especiales, requiere de una planificación estratégica, para poder hacer de esta práctica una realidad que produzca beneficios para la sociedad, y no sea 
concebida sólo como un acto de beneficencia que lleve al fracaso o produzca deserción. Se busca lograr una integración socio laboral que permita a estas personas participar en la vida corriente de la comunidad, a través de actividades productivas, teniendo la capacidad, el deseo y la oportunidad.

\section{Referencias Bibliográficas}

Angarita, D. (2014). Rehabilitación integral: Un análisis de contenido de marco normativo de apoyo a la discapacidad. Tesis de maestría no publicada. Universidad Nacional de Colombia, Bogotá, D.C., Colombia.

Banco Mundial (2009). Discapacidad y desarrollo inclusivo en América Latina y el Caribe. La Discapacidad: Un obstáculo para el desarrollo. Recuperado de http://web.worldbank.org/ contentMDK:20286156 pagePK:210058 piP K:210062 theSitePK:282699, 00.html

Barnes, C. (1998). Las teorías de la discapacidad y los orígenes de la opresión de las personas discapacitadas en la sociedad de occidente. En: Discapacidad y sociedad. Comp. L Barton Cap. III, pp. 59-76. Madrid: Morata S.L.

CIF (2001) Clasificación Internacional del Funcionamiento de la Discapacidad y de la Salud Recuperado de https://aspace.org/assets/uploads/publicaciones/e74e4-cif_2001.pdf

Cuervo, C. y Trujillo, A. (2004). Evolución de la visión conceptual sobre discapacidad e inclusión social en la Maestría en Discapacidad e Inclusión Social. En: Discapacidad e Inclusión Social. Reflexiones desde la Universidad Nacional de Colombia. Eds. Cuervo, C.; Trujillo, A.; Vargas, D.; Mena, B. y Pérez, L. 1ª edición, pp. 29 - 40. Bogotá, D.C.: Universidad Nacional de Colombia.

Cuevas, A. (2013) Guía básica para publicar artículos en revistas de investigación Universidad de Celaya México Recuperado de http://www.udec.edu.mx/i2012/investigacion/201306_Guia_publicar_articulos_de_investigacion.pdf

Jiménez, A y Agustín L (2005) la discriminación por motivos de discapacidad Recuperado de http://www.ite.educacion.es/formacion/materiales/126/cd/unidad_2/material_M2/saberma s1.pdf

Laloma, M. (2007). El empleo protegido en España. Análisis de la normativa legal y logros alcanzados. Colección Telefónica Accesible. Madrid: Ediciones Cinca. Recuperado el 23 de agosto de 2013 de 
https://www.mercadis.com/pdf/Empleo_protegido_normativa_legal_logros_ alcanzados.pdf

Organización de las Naciones Unidas - ONU. (2011). Convención sobre los Derechos de las

Personas con Discapacidad. Recuperado de

http://www.un.org/esa/socdev/enable/documents/tccconvs.pdf

Organización de las Naciones Unidas - ONU. (1948). Declaración Universal sobre los Derechos

Humanos. Recuperado de http://www.oecd.org/els/emp/34808105.pdf

Organización Internacional del Trabajo - OIT. (2014). Tendencias Mundiales del Empleo 2014.

¿Hacia una recuperación sin creación de empleos? Recuperado de http://www.ilo.org/wcmsp5/groups/public/---dgreports/---dcomm/---

publ/documents/publication/wcms_234111.pdf

Organización Mundial de la Salud - OMS y Banco Mundial (2011). Informe Mundial sobre la Discapacidad.

Recuperado

de

ttp://www.who.int/disabilities/world_report/2011/summary_es.pdf

Padilla A. (2010). Discapacidad: contexto, concepto y Modelos. International Law: Revista Colombiana de Derecho Internacional. N. 16, pp. 381-414. Recuperado de http://www.redalyc.org/articulo.oa?id=82420041012

Palacios, A. (2008). El Modelo social de discapacidad: orígenes, caracterización y plasmación en la Convención Internacional sobre los Derechos de las Personas con Discapacidad. Colección CERMI No. 36. Madrid: Grupo Editorial Cinca.

Parra, C. A. (2004). Derechos humanos y discapacidad. Colección Textos de Jurisprudencia. Primera Edición. Bogotá, D.C.: Centro Editorial Universidad del Rosario.

Peñas, O. L. (2004). Trabajo y productividad en el escenario de la inclusión/exclusión social. En: Discapacidad e Inclusión Social. Reflexiones desde la Universidad Nacional de Colombia. Eds. Cuervo, C.; Trujillo, A.; Vargas, D.; Mena, B. y Pérez, L. 1ª edición, pp. 341-356. Bogotá, D.C.: Universidad Nacional de Colombia.

Rodríguez, C. y Rico, L. (2009). Dis-Capacidad y derecho al trabajo. Primera Edición. Bogotá D.C.: Ediciones Uniandes. Colombia. Recuperado de http://cijus.uniandes.edu.co/publicaciones/ultimaspublicaciones/discapacid adyderechoaltrabajo.pdf 
Stang, M. (2011). Las personas con discapacidad en América Latina: del reconocimiento jurídico a la desigualdad real. Centro Latinoamericano y Caribeño de Demografía (CELADE) Recuperado de http://www.eclac.org/publicaciones/xml/6/43186/lcl3315-P.pdf

Vidal, R. y Cornejo, C. (2012). Empleo con apoyo: una estrategia de inserción laboral para jóvenes con discapacidad intelectual. Convergencia Educativa. Pp. 113-127. Recuperado de http://www.convergenciaeducativa.cl/principal/wp-content/uploads/01- empleo.pdf 